\title{
Bioremidial measures for parameters of Pharmaceutical outlets At Jigini, Hoskote Industrial area
}

Shwetha.A ${ }^{1}$, Dr.Sampath Kumar M C ${ }^{2}$ and Dr.M Rajyalakshmi ${ }^{3}$

\begin{abstract}
Environmental pollution remains a serious issue in the developing world, affecting the lives of billions of people, reducing their life expectancy and damaging children's growth and development. The discharge of effluents from pharmaceutical industries into the environment could easily lead to contamination of surface and groundwater with diverse drug active ingredients, the long effect of which may be detrimental to the health of those that use the water. Out of various pharmaceutical industries in India, the study area chosen is Hoskote. A sample of surface water around the industries at various points is collected and a composite sample is prepared. Analysis of water was done for pharmaceutical parameters like phenol, phosphate, chromium, BOD, COD, $\mathrm{p}^{\mathrm{H}}$, Total Solids, Coliforms and Sulphides. The result is then compared with BIS standards. Ground water quality for pharmaceutical parameters were within the permissible and surface water samples in Hoskote industrial area and its environs have phosphate beyond the permissible limit as prescribed by Indian Standards. The mathematical model precisely shows the variation of BOD and phosphate with respect to time. Suitable biotechnical remedied are followed to remove Phosphate from pharmaceutical effluents. The parameters above the maximum permissible limits such as Phosphate was removed up to $90 \%$ using Cyanobacteria within 15 days.

Keywords - Pharmaceutical Parameters, Mathamatical Model, Ground Water, Bioremediation, Ground water.
\end{abstract}

\section{INTRODUCTION}

Industry is the production of goods or related services within an economy. The major source of revenue of a group or company is the indicator of its relevant industry. Pharmaceutical waste is one of the major complex and toxic industrial wastes. The pharmaceutical industry employs various processes and a wide variety of raw materials to produce an array of final products needed to fulfill national demands. Generation of wastewater in industrial processes is sometimes unavoidable and in most of the cases a process to reduce the organic load. To remove part of the organic load, biological processes are usually used, because they are more economic than chemical processes. Many researchers have tried to find out

${ }^{1}$ Department of Civil Engineering Global Academy of Technology, Bangalore, Karnataka, India

${ }^{2}$ Department of Civil Engineering BMS College Of Engineering, Bangalore, Karnataka, India

${ }^{3}$ Department of Civil Engineering BMS College Of Bio-Technology, Bangalore, Karnataka, India 
different treatments for pharmaceutical wastewater to approaches worldwide; here an attempt is made to review some such researches done, with particular reference to Pharmaceutical wastewater effluent, in India and abroad also.

Pharmaceutical industry represents a range of industries with operation and processes as diverse as its product .Hence effluents coming from pharmacy industries vary from industry to industry. Thus it is almost impossible to describe a typical pharmaceutical effluent because of such diversity. Waste water is generally evaluated in terms of temp, $\mathrm{pH}$, Total suspended solid (TSS), BOD, COD, Oil \& grease, chlorides and sulphates. Various treatment methods for wastewater found in the literature have contributed greatly to our knowledge regarding the fate of these compounds in different treatment systems.

Generalizing compound behavior in these systems would allow further characterization of the fate and risk associated with water in the environment, yet this description of trends is hindered by the wide variation in removal efficiencies across therapeutic classes, treatment processes, and even among separate studies for the same individual compounds. The majority of studies summarized used "removal" to describe the elimination of parent pharmaceuticals. The disappearance of the parent compound cannot be considered synonymous with complete removal. If adequate controls for physical and chemical removal mechanisms are in place, the loss of the parent compound indicates biotransformation of an unknown degree and not necessarily mineralization. Only monitoring for metabolites or end products of mineralization can provide information about the degree of biotransformation. The wastewaters from pharmaceutical manufacturing plants is more problematic due to number of different treatment method. Effluent Treatment Plants (ETP) are used by companies in the pharmaceutical industry to purify wastewater and remove pollutant from it. These plants are used by all companies for environment protection.

\section{OBJECTIVE OF THE STUDY}

- To check the status of the Jigini, Hoskote Industrial area.

- Assessment of Ground and surface water quality for parameters of Pharmaceutical outlets such as $\mathrm{pH}$, BOD, COD, phosphate, sulphate. Chromium, E-Coli etc.

- Analysis of data and to develop a regression model to study the effects of different components and to predict the future behavior of the parameters.

- Suggesting suitable Bioremedial measures for specific pollutants.

\section{III.REVIEW OF LITERATURE}

[1] Karl J. Ottmar (2013) Conducted a study on " Evaluation of a Prediction Model for Influent Pharmaceutical Concentrations" This research attempts to evaluate a previously developed model for predicting influent concentrations of prescription pharmaceuticals and understand why some drugs are more accurately predicted than others. It also investigates the impact of demographics on influent drug concentrations in municipal wastewater treatment plants (WWTPs). Samples from two WWTPs in the southeastern United States indicate that the model generates concentration estimates that are accurate to within at least one order of magnitude for a diverse set of drug compounds. Additionally, strategically timed sampling at college-town WWTPs, wherein 19-25\% of the population comprises students ages $18-$ 22, reveals that the influent concentrations of several drugs (atorvastatin, simvastatin, rosuvastatin, and metformin) generally prescribed to older-than-average persons increase while students are absent on holiday, whereas the influent concentration of one drug (17 $\alpha$-ethynyl estradiol) prescribed to younger- 
than-average persons decreases. These observations reveal the impacts of demographics on prescription drug concentrations in WWTP influents, offering some explanation for the wide variability among previously measured influent drug concentrations. It was also observed that hospital size is generally correlated with increased influent drug concentrations.

[2] P. Chevalieret. al. (2000) Conducted a study on on "Nitrogen and phosphorus removal by high latitude mat-forming cyanobacteria for potential use in tertiary wastewater treatment" biological wastewater treatment systems for cold climate areas four strains of filamentous, mat-forming cyanobacteria isolated from Arctic and Antarctic environments were evaluated for their nutrient stripping and growth capabilities. A tropical strain, Phormidium bohneri, known for its excellent performance in wastewater treatment, was used as a comparison. Experiments were done in artificial media under controlled batch culture conditions to avoid interactions with indigenous microorganisms such as bacteria and protozoa. The culture medium simulated real effluents containing high concentrations of nitrate and phosphate. Their results indicate that tertiary biological wastewater treatment at low temperatures $(5 \circ \mathrm{C})$ cannot be anticipated with the polar strains tested, because they are psychrotrophic rather than psychrophilic and thus grow too slowly under conditions of extreme cold. However, it appears that these cyanobacteria would be useful for wastewater treatment at moderately cool temperatures (c. $\left.15^{\circ} \mathrm{C}\right)$, which are common during spring and fall in northern climates.

[3] P. K. Roy et. al. (2014) Conducted a study on on "Study of impact on surface water and groundwater around flow fields due to changes in river stage using groundwater modeling system" explains the impact of pharmaceutical wastes on groundwate. Excessive ground water withdrawal can lead to ground water depletion, and this may have serious social and economic consequences. Attempts to limit groundwater pumping have been commonly based on the concept of safe yield. In this study, in order to evaluate safe yield, short- and long-duration pumping tests have been performed at four different sites (Purulia District, India) on Damodar River bed. The lithological survey was carried out along the river bed at regular intervals from $500 \mathrm{~m}$ to $10.5 \mathrm{~km}$, covering a total stretch of $10-\mathrm{km}$ up-stream and 0.5 $\mathrm{km}$ down-stream, to determine the soil profile and other soil characteristics. The points, where the maximum depth of porous medium was obtained, were selected for carrying out the pumping yield tests. The appropriate hydrogeologic approaches were employed to estimate the values of aquifer parameters, viz., specific yield (Sy), transmissivity(T), and hydraulic conductivity $(\mathrm{K})$ for the aforesaid sites under study, which were found to be in the range of $0.043-0.175,2082-3983$, and 219-603 m/day, respectively. A hypothetical aquifer-stream water interaction system has been developed using GMS software (groundwater modeling system) not only to represent the hydraulic head fluctuations in the groundwater system around well fields but also to quantify the flow rate due to change in river stage, recharge due to rainfall, and also to determine how the surface water could affect groundwater due to pumping .

[4] Sanjay Kumar Dubey et.al (2011) Conducted a study on on " Potential use of cyanobacterial species in bioremediation of industrial effluents" This study investigated the potential degradation of industrial effluents by environmental species of cyanobacteria. Cyanobacterial species isolated from the Pharmaceutical and Textile industries Mandideep, Bhopal were exposed. Isolation and utilization of the locally generated cyanobacterial biomass for remediation of private industrial activities will generate a 
source of revenue in Bhopal localities. Biodegradation and biosorption capacity of some potential cyanobacterial species: Oscillatoria sp., Synechococcus sp., Nodularia sp., Nostoc sp. and Cyanothece sp. dominated the effluents and mixed cultures showed varying sensitivity. Contaminant was removed by all the species, either as individuals or mixtures, at both concentrations. The abundance of cyanobacteria in this effluent was due to favorable contents of organic matter, rich calcium and nutrients such as nitrates and phosphates with less dissolved oxygen. Removal efficiencies of the different contaminants were evaluated and compared. Results confirmed the high efficiencies of the investigated species for the removal of the target contaminants which were species and contaminant-dependent. The contaminants removal efficiency (RE) percentage of cyanobacterial species ranged between 69.5 and $99.6 \%$ with a maximum of 97.0 to $99.6 \%$ at $5 \mathrm{ppm}, 83.9 \%$ and $99.7 \%$ at $10 \mathrm{ppm}$ and maximum between 95.5 and 99.7\%. Mixed culture RE percentages ranged between 91.6 and $100 \%$ at $5 \mathrm{ppm}$ with a maximum range of 99.3 to $100 \%$, while at $10 \mathrm{ppm}$, the RE percentage ranged between 90.4 and $100 \%$, with a maximum range of 96.0 to $100 \%$. Results indicate the potential of natural resources as efficient agents for pollution control.

\section{MATERIALS AND METHODOLOGY}

\section{Details Of The Study Area}

It is a taluk in Bangalore Rural District. Headquartered at the Hoskote town, it consists of five hoblis Anugondanahalli, Jadigenahalli, Kasaba, Nandagudi and Sulibele. Agriculture, apiculture and horticulture are primary occupations of people here, although the industrialization in the recent times in Hoskote and places around has thrown up new opportunities for the people. Hoskote is the largest taluk in Karnataka having 333 villages. Hoskote town is the headquarters of the Hoskote Taluk, and lies at the intersection of NH-4 and NH-207 and as such is a busy town with both resident and floating population. Hoskote has a medical college and research institute known as MVJ Medical College \& Research Centre. Hoskote is known for its moderate climate throughout the year. The town is around $900 \mathrm{~m}$ above sea level making its climate usually 1 or 2 degrees cooler than Bangalore.

\section{Yele Mallappa Shetty Lake}

- The study area lies in the North part of Bangalore, at the

- Latitude $13^{\circ} 8^{\prime}, 13^{\circ} 12^{\prime}$

- Longitude $77^{\circ} 33^{\prime}, 77^{\circ} 37^{\circ}$.

- The altitude varies from $860-954 \mathrm{~m}$ in the study area covering in topographical map of $57 \mathrm{G} / 12$ NE of 1:25000 scale.

\section{V .METHODOLOGY}

Based on study area appropriately 30 to 35 groundwater sampling points and surface sources was selected for analyzing the water quality parameters in watershed. Coordinates of each sample point locations was recorded in field through handset GPS. The water quality parameters included $\mathrm{pH}$, BOD3, COD, TSS, Phenolics, Sulphide, Phosphate and Species of Colliform in this study. These water quality parameters of each sample were analyzed in laboratory by using appropriate standard methods, tabulations are done using excel sheet and led to statistical treatment. 
A mathematical model is a description of a system using mathematical concepts and language. The process of developing a effects of different components, and to make predictions about behavior. Based

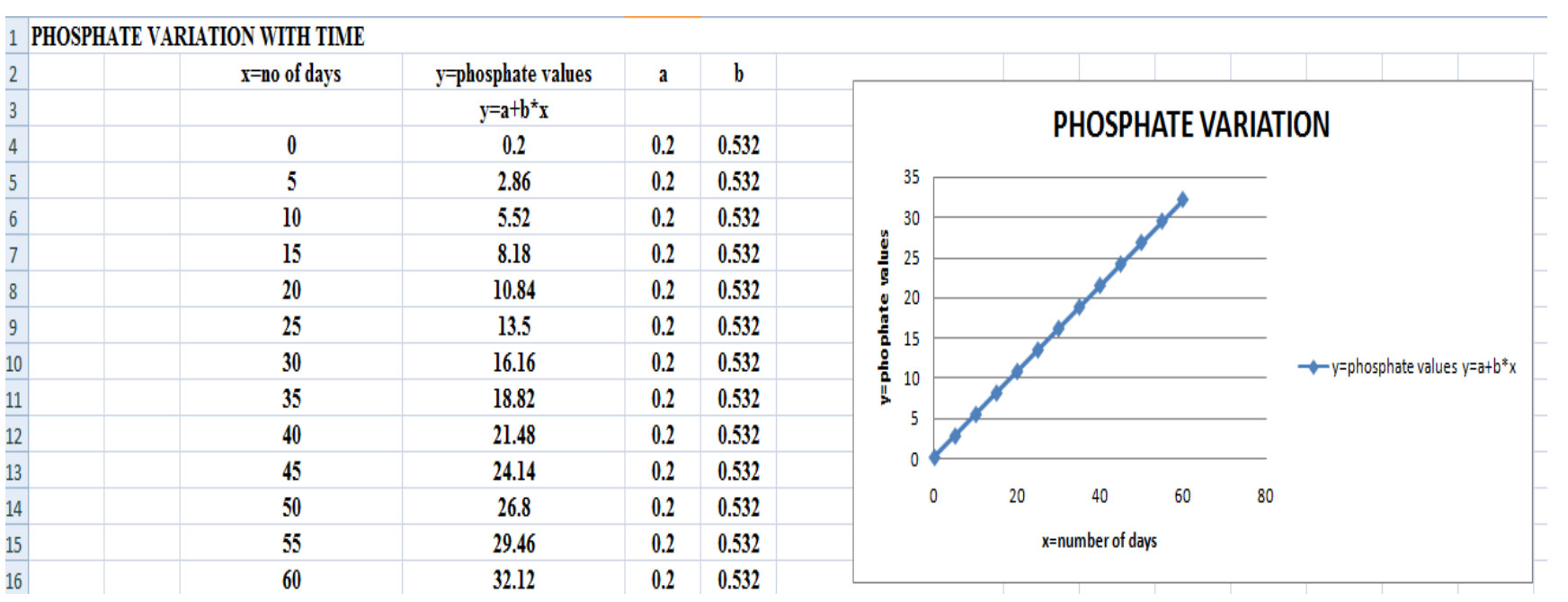

on the res ults obt ain ed, to dev elo $\mathrm{p}$ a $\mathrm{Re}$ gre ssio

model was developed using advanced scientific tool. A model may help to explain a system and to study the future trends. Then finally Providing a Bio-Technical solutions for specific environmental parameters is carried out by cyanobacteria.

Parameters Tested-----COD, BOD, pH, Phosphate, Chromium, Sulphides, Total Suspended Solids, EColi and Phenols.

\section{RESULT OF THE TREATMENT}

BOD VARIATION WITH TIME @27 C

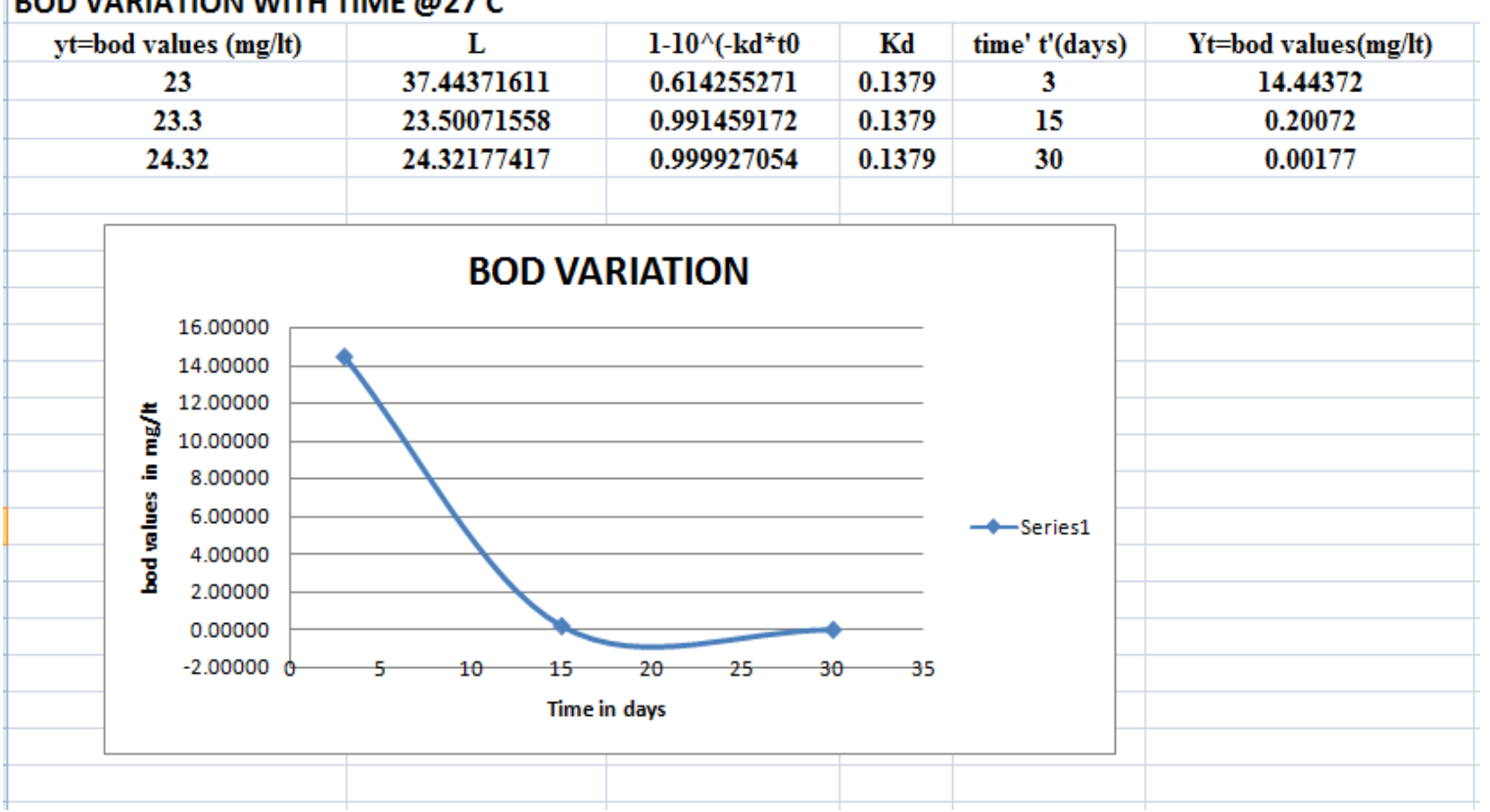

conclusions were drawn by analysis and microbiological treatment.
Variation Of BOD with Time.

Variation

Of Phosphate With Time

\section{CONCLU SIONS}

The following 
- The groundwater quality was within the limits for pharmaceuticals parameters near Cipla industrial area.

- The surface water quality showed that BOD, COD and phosphate exceeded the permissible limits.

- Bio-remedial measure which is suggested was found to be effective and economical.

- Cyanobacteria was very effective in removing phosphate from pharma effluents to about $90 \%$ within 15 days. .

- The mathematical model precisely shows the variation of BOD and phosphate with respect to time.

\section{ACKNOWLEDGEMENTS}

I am thankful Professor and Head, Dept of Civil Engineering, and Head, Dept of Bio Technology, Principal of Global Academy Of Technology and BMS College of Engineering for their timely help rendered and the immense support extended for the submission of this paper.

\section{REFERENCES}

[1] Karl J. Ottmar, P.E., M.ASCE1; Lisa M. Colosi, M.ASCE2; and James A. Smith, P.E., M.ASCE3 "Evaluation of a Prediction Model for Influent Pharmaceutical Concentrations"Journal of Environmental Engineering, Volume 139, Issue 7 (July 2013).

[2] P. Chevalier1, D. Proulx1,2, P. Lessard1,3 , W.F. Vincent4\& J. de la Noüe1,2* "Nitrogen and phosphorus removal by high latitude mat-forming cyanobacteria for potential use in tertiary wastewater treatment" Journal of Applied Phycology 12: 105-112, 2000.

[3] P. K. Roy • S. S. Roy • A. Giri • G. Banerjee • A. Majumder • A. Mazumdar " Study of impact on surface water and groundwater around flow fields due to changes in river stage using groundwater modeling system" Springer, Published Online 07 may (2014).

[4] Sanjay Kumar Dubey* Jaishree Dubey, Sandeep Mehra, Pradeep Tiwari and A. J. Bishwas ““” Potential use of cyanobacterial species in bioremediation of industrial effluents" African Journal of Biotechnology Vol. 10(7), pp. 1125-1132, 14 February, 2011

[5] APHA, American Public Health Association, American Water Works Association and Water Pollution Control Federation (1989) Standards Methods for the Examination of Water and Wastewater, Washington, DC.

[6] Blier R, Laliberté G, de la Noüe J (1996) Production of the cyanobacterium Phormidium bohneri in parallel with epuration of a dairy anaerobic effluent. Process Biochem. 31: 587-593.

[7] Hu Q, Westerhoff P, Vermaas W (2000) Removal of nitrate from groundwater by cyanobacteria: Quantitative assessment of factors influencing nitrate uptake. Appl. environ. Microbiol. 66: 133-139.

[8] Laliberté G, Lessard P, de la Noüe J, Sylvestre S (1997) Effect of phosphorus addition on nutrient removal from wastewater with the cyanobacterium Phormidium bohneri. Bioresource Technol. 59: 227-233.

[9] Simon RD (1987) Inclusion bodies in the cyanobacteria: cyanophycin, polyphosphate, polyhedral bodies. In Fay P, Van Baalen C (eds), The Cyanobacteria. Elsevier Science Publishers B.V., Amsterdam, Netherlands: 199-226.

[10] Vaara T, Vaara M, Niemela S (1979). Two improved methods for obtaining axenic cultures of cyanobacteria. Appl. environ. Microbiol. 38: 1011-1014. 